\title{
Characterizing ontogenetic habitat shifts in marine fishes: advancing nascent methods for marine spatial management
}

\author{
Ronen Galaiduk iD ${ }^{1,6}$ Ben T. Radford, ${ }^{2,3,4}$ Benjamin J. Saunders iD, 1 \\ Stephen J. Newman, ${ }^{5}$ and Euan S. Harvey id 1 \\ ${ }^{1}$ Department of Environment and Agriculture, Curtin University, Kent Street, Bentley, Western Australia 6845 Australia \\ ${ }^{2}$ Australian Institute of Marine Science, The University of Western Australia, 35 Stirling Highway, \\ Crawley, Western Australia 6009 Australia \\ ${ }^{3}$ The UWA Oceans Institute, The University of Western Australia, 35 Stirling Highway, Crawley, Western Australia 6009 Australia \\ ${ }^{4}$ School of Earth and Environment, The University of Western Australia, 35 Stirling Highway, Crawley, \\ Western Australia 6009 Australia \\ ${ }^{5}$ Western Australian Fisheries and Marine Research Laboratories, Department of Fisheries, Government of Western Australia, \\ P.O. Box 20, North Beach, Western Australia 6920 Australia
}

\begin{abstract}
Niche requirements and habitat resource partitioning by conspecific fishes of different sizes are significant knowledge gaps in the species distribution modelling domain. Management actions and operations are typically concentrated on static habitats, or specific areas of interest, without considering movement patterns of species associated with ontogenetic shifts in habitat usage. Generalized additive models were used to model the bodylength-habitat relationships of six fish species. These models were used to identify subsets of environmental parameters that drive and explain the continuous length-habitat relationships for each of the study species, which vary in their degree of ecological and/or commercial importance. Continuous predictive maps of the length distributions for each of the six study species across approximately $200 \mathrm{~km}^{2}$ of the study area were created from these models. The spatial patterns in habitat partitioning by individuals of different body lengths for all six study species provide strong evidence for ontogenetic shifts. This highlights the importance of considering ontogenetic processes for marine spatial management. Importantly, predictive hotspot maps were created that identify potential areas that accumulate individuals of similar life stages of multiple species (e.g., multispecies nursery areas). In circumstances where limited resources are available for monitoring and management of fish resources, predictive modelling is a valuable tool for studying previously overlooked processes such as ontogenetic habitat shifts. Predictive modelling provides crucial information that elucidates spatial patterns in community composition across mosaics of benthic habitats. This novel technique can contribute to the spatial management of coastal fish and fisheries by identifying areas that are important for different life history stages of multiple fish species.
\end{abstract}

Key words: demersal reef fish; habitat shifts; Houtman Abrolhos Islands; natural resource management; nursery areas; predictive modelling; species distribution models; species interactions.

\section{INTRODUCTION}

The biogeographic distribution, assemblage composition, and abundance of marine organisms are known to be tightly associated with habitat type and its complexity and variability (Halpern et al. 2005, Kingsford and Carlson 2010). The habitat is defined as an arrangement of environmental conditions that influences responses in the presence, abundance, growth, and other important life-history traits of an organism (i.e., environmental niche; Hutchinson 1957, Martinez-Meyer et al. 2013). Habitat associations can vary among species and also within life history stages of the same species (Jones 1984a, Compton et al. 2012). Species that are habitat specialists are inherently more susceptible to change in

Manuscript received 2 May 2016; revised 9 February 2017; accepted 10 April 2017. Corresponding Editor: Eric J. Ward.

${ }^{6}$ E-mail: ronen.galaiduk@curtin.edu.au habitat quality and cover as a result of climate change or other anthropogenic stressors, such as sedimentation and eutrophication (Munday 2004). This is particularly relevant for species that are dependent on a specific habitat for juvenile recruitment (Jones et al. 2004). For example, when canopy forming macroalgal fields and coral reefs co-occur, macroalgal fields can serve as recruitment and juvenile habitats for fish taxa that are typically associated with coral reefs as adults (Evans et al. 2014).

Many fishes utilize a mosaic of habitats on a daily basis (Boström et al. 2011) and only few are confined to a single juvenile habitat (Nagelkerken 2007). Daily animal movements in search for food or shelter spatially connect a mosaic of adjoining habitats (Nagelkerken et al. 2015). Connectivity between habitat patches could be also facilitated by ontogeny because of changing resource requirements over time (Kimirei et al. 2013). For any given species, as an individual grows its morphology and 
behavior change, as does its prey size and type (Lukoschek and McCormick 2001, Kimirei et al. 2013). This often requires a change in habitat to meet energy and resource needs (Huijbers et al. 2015). These continuous changes in environmental niche requirements with ontogeny and patterns of population connectivity are a crucial link for understanding the processes that underpin community composition across a mosaic of adjoining benthic habitats (Compton et al. 2012, Nagelkerken et al. 2015). Improving our understanding of size-specific environmental niche partitioning among conspecifics and mapping the key areas of the seascape that are important for multiple species can be of particular interest for an effective spatial management of species.

Marine spatial management benefits from an understanding of species-habitat relationships such that the design and placement of spatial area closures can be optimized (e.g., Possingham et al. 2000). However, large scale spatial sampling for monitoring and assessment is often limited to a few locations because of resource constraints (Costa et al. 2014). Being able to reliably predict ecological information across broader geographical areas is thus important, relevant and instructive (Schmiing et al. 2013). To this end, species distribution models are a powerful tool, as they combine observations of species occurrence or abundance with environmental and/or spatial variables. Species distribution models are widely used in terrestrial, freshwater and marine environments to support spatial planning arrangements (Elith and Leathwick 2009, Moore et al. 2009). Furthermore, the results of predictive modelling can be readily illustrated in GIS and areas of specific interest for spatial management identified for individual or multiple species (Schmiing et al. 2013, Costa et al. 2014).

Generalized additive models (GAMs) are particularly suitable for predicting complex, often non-linear responses of marine species to environmental predictors (Leathwick et al. 2006). They have become commonly applied method for modelling fish-habitat relationships. Therefore, they are a natural choice to examine the size-specific shifts in habitat use or partitioning of habitat resources among conspecifics. This topic has received little attention in species distribution modelling (but see Lauria et al. 2011, Martin et al. 2012 for examples using Generalized linear models GLMs). Utilizing body length as the continuous response variable in models, can provide a more realistic representation of ecological patterns than binning into size classes (Austin 2007). Models of size specific habitat associations can help to identify key areas of the seascape that are crucial for different life-history stages of a single species or for multiple species (e.g., nursery areas). Mapping, followed by management or protection of such areas, may result in higher survival of vulnerable life stages (Dugan and Davis 1993), and by preserving seascape connectivity patterns between nursery areas and adult populations it is possible to enhance the abundance of target and other fish species that rely on healthy ecosystem functioning (Olds et al. 2014).
This study sets out to improve our understanding of the spatial ecology of the modelled species by identifying environmental parameters that best determine ontogenetic environmental niche partitioning among conspecific individuals. The body length measurements of individual fishes will be modelled utilizing GAMs in order to produce predictive maps of the continuous spatial distributions of conspecifics across the study area. In addition, we will create predictive hotspot maps as single GIS layers to identify critical areas for different life-history stages of multiple species. Using these maps we aim to synthesize complex spatial distribution patterns of multiple species with varying life history characteristics into a simple resource for effective spatial management. This novel approach of modelling continuous body length of individual fishes in combination with the flexibility of GAMs is likely to improve the ecological realism of predictive modelling and the appeal of quantitative spatial ecology to marine resource managers.

\section{MATERIALS AND METHODS}

\section{Study area}

The Houtman Abrolhos Islands are four clusters of islands (consisting of a total of 122 islands) approximately $60 \mathrm{~km}$ offshore of the central-west coast of Western Australia. The islands run parallel to the mainland in a north-south orientation and span $\sim 100 \mathrm{~km}$. They exhibit a high species diversity of fishes with 184 species recorded, belonging to 42 genera derived from both tropical and temperate origins (IMCRA 1998). The warm, southward flowing Leeuwin Current supports the southernmost coral reefs in the Indian Ocean, giving this location a unique blend of temperate, tropical and Western Australian endemic fish species (Hutchins 2001, Watson et al. 2009). This biodiversity rich area is influenced by environmental changes (Bornt et al. 2015) including a recent marine heat wave (Pearce and Feng 2013). We surveyed the fish assemblage composition and developed detailed habitat maps in two areas that are open to fishing. Area 1 to the north of the Pelsaert Island group and Area 2 to the east of the Easter group (Fig. 1).

\section{Fish data collection and study species selection}

Baited remote underwater stereo-video systems (stereo-BRUVs) were used to survey fish assemblages in the study area between the 15 and 19 May 2007. Design, calibration, and use of the stereo-BRUVs are presented in detail in Harvey and Shortis $(1995,1998)$ and Harvey et al. (2013). To ensure that sampling replication was appropriate, sampling was spatially stratified according to the size of the study location and depth. In addition, sampling was randomly assigned and distance controls used to avoid spatial autocorrelation between samples (see Radford et al. 2008 for further details on site 


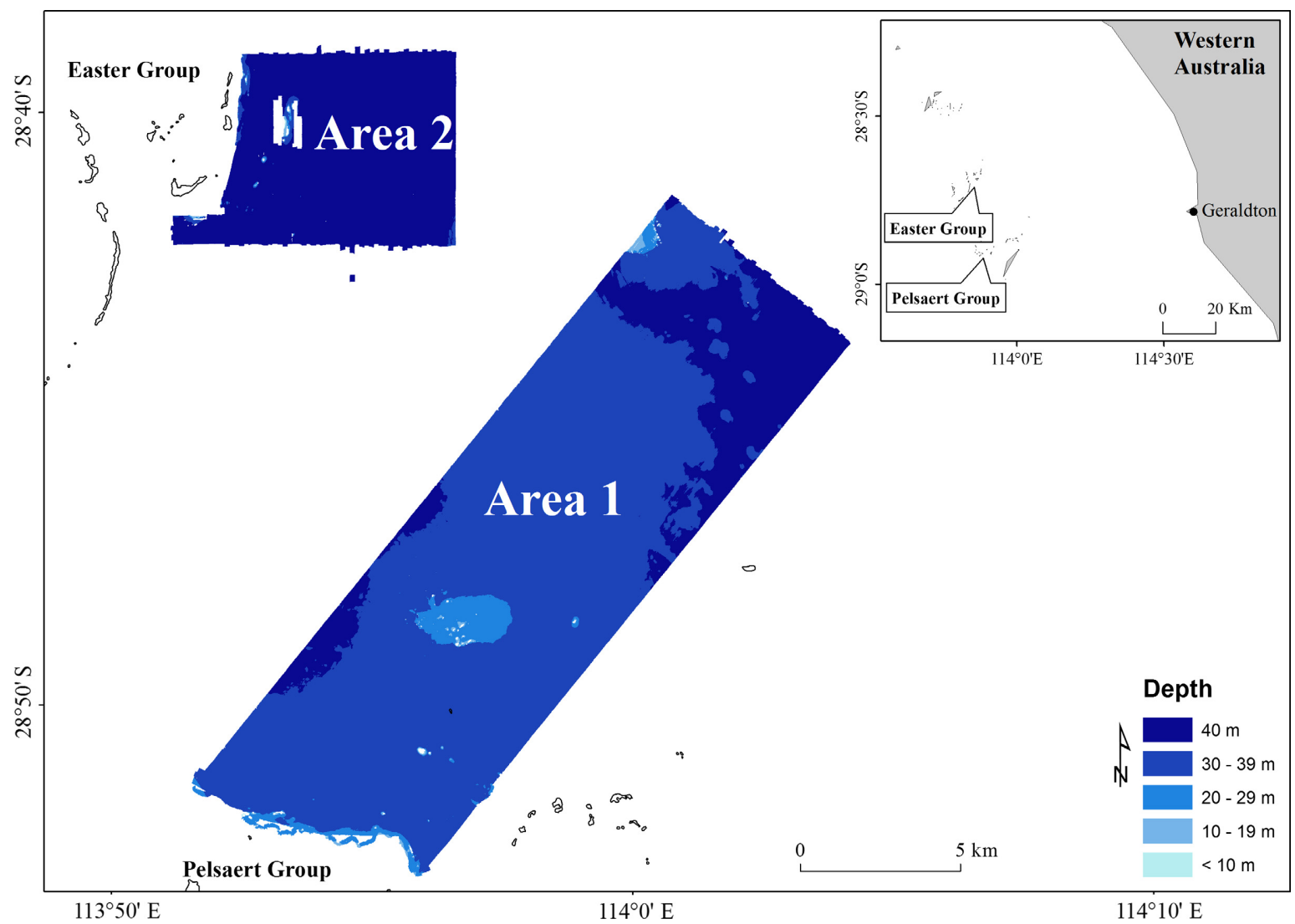

Fig. 1. Map of the two study areas, north of the Pelsaert Group (Area 1) and east of the Easter Group (Area 2). Inset: general location of the Houtman Abrolhos Archipelago off the coast of Western Australia. [Color figure can be viewed at wileyonlinelibrary.com]

selection criteria). A total of 195 video recordings were analyzed using the software EventMeasure Stereo (SeaGIS Pty Ltd, Victoria, Australia). The species chosen for modelling were among the most commonly recorded in the study area and characterized by contrasting life histories, or were commercially important (Table 1). The fork length of each fish was measured with precision constraints set to a $10 \%$ cut off, which is achievable using stereo-BRUVs (Harvey and Shortis 1995, Harvey et al. 2002).

\section{Habitat mapping}

Approximately $200 \mathrm{~km}^{2}$ of the seafloor in the study area between depths of 10 and $40 \mathrm{~m}$ was hydroacoustically surveyed using a Reson 8101 Multibeam (Fugro Pty Ltd, Perth, Australia) between 15 and 23 November 2006. In addition, underwater towed video footage was collected over more than 100 linear $\mathrm{km}$ between the 3 and 8 March 2007. The hydroacoustic surveys provided bathymetric information and a coarse distinction between various substrate textures, whereas the towed video imagery provided "ground truthing" for the multibeam and allowed for fine scale habitat definition. The hydroacoustic maps and observations recorded from towed videos were combined in a statistical modelling framework using Classification and Regression Trees to predict the probabilities of occurrence of substrate and biota in areas with no observations (see Radford et al. 2008 for detailed methods). For both sites, all identified benthic classes were mapped, including sediment texture and relief, reef structures, different types of vegetation and sessile invertebrates, providing a total of 21 variables (Table 2). All probabilities of occurrence for benthic habitat and biota from the modelling were then predicted on a $2.5 \mathrm{~m}$ grid in ArcGIS (ESRI, Redlands, CA, USA) using GDA94 datum MGA zone 50 equal area projections, allowing future querying and intersecting with the fish sampling data.

\section{Preliminary data exploration}

In order to achieve a continuous distribution of the response variable fish length for each species, fork length measurements from both sites were analyzed together. All exploratory and statistical analyses were performed using the packages lattice, mgcv, gamclass, and raster in $\mathrm{R}$ software (version 3.2.0; $\mathrm{R}$ Core Team 2014). The initial data exploration followed procedures outlined in Zuur et al. (2007, 2010), examining potential outliers, 


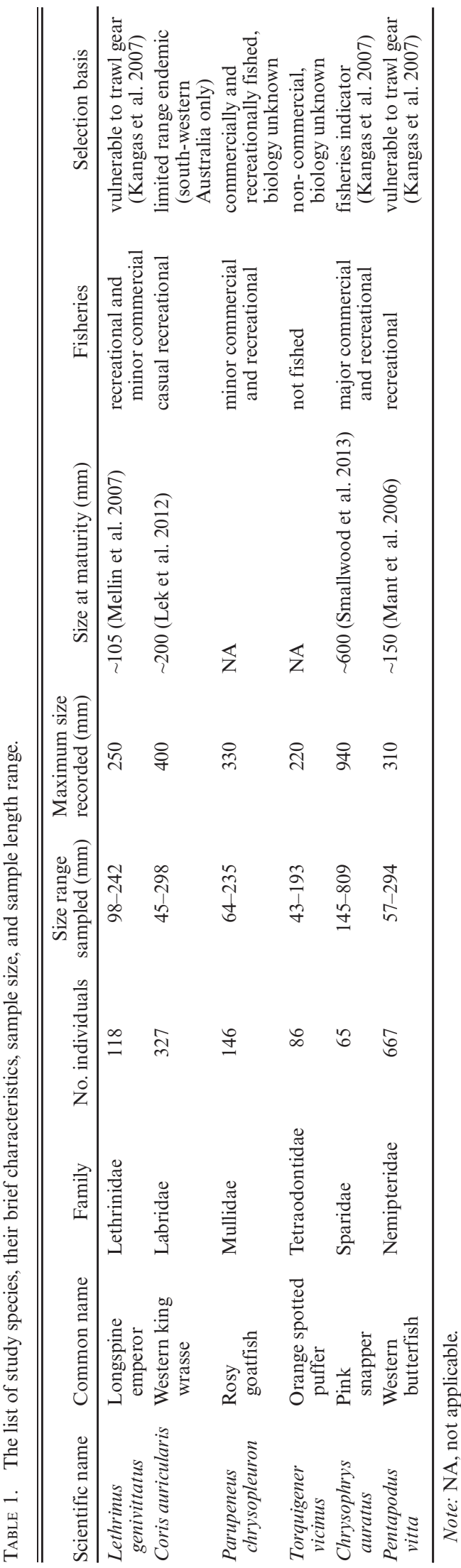

homogeneity and co-linearity of covariates for individual fish species sequentially. For each species-specific data subset, the explanatory variables with Spearman's rank correlation $>0.7$ and/or explanatory variables with a high percentage of zeroes $(>90 \%)$, were excluded from further analyses of the specific subset (Moore et al. 2011).

\section{Model fitting, cross-validation, and final variable selection}

The final subset of environmental variables was fit into a GAM for each species with a gamma error distribution with $\log$ link function (Hastie and Tibshirani 1990, Wood 2006). The predicted habitat data has probabilities of occurrence ranging from 0 to 1 , as such, all explanatory variables were modelled with smoothers (knots) limited to $k=3$. The number of knots determines the smoothness of the curve; the fewer knots used, the more smooth the curve (Wood 2006, Sagarese et al. 2014). In addition, each model formula included a gamma $=1.4$ loading to place a heavier penalty on each effective degree of freedom to counteract overfitting without compromising the model fit (Zuur et al. 2009, Drexler and Ainsworth 2013).

The smoothing was performed automatically with cubic regression splines and a combination of shrinkage and double penalty approaches during the model fitting process (Marra and Wood 2011). Shrinkage procedures are continuous processes, carrying out variable selection in one single step in such a way that smooth terms making no contribution to the model can be penalized away completely, and are considered to be a valid method for a variable selection in terms of both stability and prediction (Wood 2006, Hesterberg et al. 2008). Hypothesis testing was used for final variable selection. Where the hypothesis testing indicated non influential variables (approximate $P>0.05$ ) they were removed from the analysis and the model was refitted (Marra and Wood 2011). When smoothers exhibit a linear behavior, terms for these variables were fitted in a parametric manner. Response curves were visually inspected for ecological realism (Sagarese et al. 2014). Finally, we repeated fivefold cross validation 50 times and then calculated normalized root mean square error (normalized RMSE) to examine the magnitude of the predictive errors of all generated submodels (Potts and Elith 2006, Costa et al. 2014).

To verify an absence of residual patterns, model residuals were plotted against each predictor variable included in the final model and excluded during variable selection procedures. Spatial independence was evaluated by plotting the model residuals against the spatial coordinates. Possible influential observations, outliers, homogeneity and normality of model residuals were investigated graphically following Zuur et al. (2010).

\section{Spatial prediction of species' size distributions}

Once the final models were validated, the constrained size distributions of individual fish species were 
TABLE 2. Summary of the environmental predictors extracted from the hydroacoustic survey and the predictive modelling used for the generalized additive model fits.

\begin{tabular}{|c|c|c|}
\hline Predictor & Description and units & Predictor code \\
\hline Bathymetry & Elevation relative to the Australian Height Datum (m). & bathy \\
\hline Eastness & $\begin{array}{l}\text { Trigonometric transformation of a circular azimuthal direction of the steepest } \\
\text { slope ( } \sin (\text { aspect)), calculated on a } 3 \times 3 \text { pixel area. Values close to } 1 \text { represent } \\
\text { east-facing slope, close to }-1 \text { if the aspect is westward. }\end{array}$ & eastness \\
\hline Northness & $\begin{array}{l}\text { Trigonometric transformation of a circular azimuthal direction of the steepest } \\
\text { slope (cos(aspect)), calculated on a } 3 \times 3 \text { pixel area. Values close to } 1 \text { represent } \\
\text { north-facing slope, close to }-1 \text { if the aspect is southward. }\end{array}$ & northness \\
\hline Slope & $\begin{array}{l}\text { First derivative of elevation. Average change in elevation, calculated on a } 3 \times 3 \\
\text { pixel area (steepness of the terrain, percent rise). }\end{array}$ & slope \\
\hline Range $5,10,25 \dagger$ & $\begin{array}{l}\text { Maximum minus the minimum elevation in the local neighborhood (local relief) } \\
\text { of } 5,10,25 \mathrm{~m} \text { kernel radius. }\end{array}$ & $\operatorname{rng} 5, \operatorname{rng} 10, \operatorname{rng} 25$ \\
\hline Plan curvature & $\begin{array}{l}\text { Secondary derivative of elevation. Measure of concave/convexity perpendicular to } \\
\text { the slope, calculated on a } 3 \times 3 \text { pixel area. }\end{array}$ & plan \\
\hline Profile curvature & $\begin{array}{l}\text { Secondary derivative of elevation. Measure of concave/convexity parallel to the } \\
\text { slope, calculated on a } 3 \times 3 \text { pixel area. }\end{array}$ & prof \\
\hline Curvature & Combined index of profile and plan curvature. & curv \\
\hline Trend & The linear trend calculated across the bathymetry data set. & trend \\
\hline Low profile reef & Relief less than $1 \mathrm{~m}$. Probability of occurrence: $0-1$ & LPR \\
\hline Medium profile reef & Relief between 2 and $4 \mathrm{~m}$. Probability of occurrence: $0-1$. & MPR \\
\hline High profile reef & Relief greater than $4 \mathrm{~m}$. Probability of occurrence: $0-1$. & HPR \\
\hline Reef & Undifferentiated. Probability of occurrence: $0-1$ & reef \\
\hline Sand & Undifferentiated. Probability of occurrence: $0-1$. & sand \\
\hline Hard coral & Undifferentiated. Probability of occurrence: $0-1$. & hardcoral \\
\hline Kelp & Ecklonia radiata. Probability of occurrence: $0-1$. & kelp \\
\hline Seagrass & Undifferentiated. Probability of occurrence: $0-1$. & seagrass \\
\hline Vegetation & Undifferentiated. Probability of occurrence: $0-1$. & veget \\
\hline Sessile invertebrates & Undifferentiated. Probability of occurrence: $0-1$. & sessinvert \\
\hline
\end{tabular}

$\dagger$ Local neighborhood analysis: run on circles of kernel pixel radius 5, 10, 25. Original cell size is $2.5 \mathrm{~m}$.

predicted on 2.5-m grids using $\mathrm{R}$ and these predictions were plotted in ArcMap 10.2 (ESRI, CA, USA). In addition, to identify "hotspots" for multiple species, the continuous predictive rasters were reclassified into two size categories: juveniles/small individuals and adults/large individuals according to the known ontogeny of individual species. For Lethrinus genivittatus, Chrysophrys auratus, and Pentapodus vitta, the reclassification was based on an individual's length at maturity (Table 1). The ontogenetic shift for Coris auricularis is known to occur at approximately $200 \mathrm{~mm}$ total body length when juvenile females change sex (Lek et al. 2012), which provided the basis for raster reclassification in this study. When biological data on size distributions were not available from the literature (Parupeneus chrysopleuron, Torquigener vicinus), the size categories were assigned arbitrarily based on the observed size frequency distributions. For example, individuals with body length belonging to a first quartile were assigned into the juvenile/small size category, whereas individuals with body length belonging to a fourth quartile were assigned into adult/large category. The reclassified values were plotted again to illustrate potential multi-species "hotspot" areas, where environmental niche conditions were suitable for juvenile/small or adult/large individuals of the modelled species. For example, a hotspot would have a maximum score of 6 , corresponding to the six modelled fish species that could potentially associate with that particular area.

\section{RESUlts}

\section{Species specific models and variable selection}

Significant linear and nonlinear relationships for individual length distributions were observed for all six study species. The majority of the significant explanatory variables in the final models were associated with the physical descriptors of habitat complexity (i.e., local relief and/or slope) with some significant biotic variables (i.e., probability of occurrence of mixed undifferentiated vegetation, sessile invertebrates, and reef; Table 3 ). The deviance explained by the final models ranged from $13.6 \%$ to $54.6 \%$ (Table 3). The initial set of 21 explanatory variables was typically reduced to between two and five significant variables. The residual plots confirmed homogeneity, normality, and independence for all six focal species. For only one species, Chrysophrys auratus, slight spatial clustering of positive residuals indicated that the GAM model over-predicted the length distributions for this species. This can be attributed to the relatively small sample size ( 65 observations) and the large range in the observed sizes $(145-809 \mathrm{~mm})$ for this 
TABLE 3. Variable selection for species-specific generalized additive model with the percentage of deviance explained (Dev) and the normalized root mean square error (normalized RMSE) provided.

\begin{tabular}{|c|c|c|c|}
\hline Species & Variable selection procedure & $\operatorname{Dev}(\%)$ & Normalized RMSE (\%) \\
\hline Lethrinus genivittatus & $\begin{array}{l}\text { Length } \sim \mathrm{s}(\text { eastness })+\mathrm{s}(\text { northness })+\mathrm{s}(\text { curvature }) \\
+\mathrm{s}(\text { reef })+\mathrm{s}(\mathrm{rng} 25)+\mathrm{s}(\text { slope })+\mathrm{s}(\text { vegetation }) \\
+\mathrm{s}(\text { sessinvert })+\mathrm{s}(\text { sand })+\mathrm{s}(\text { seagrass }) \\
\text { Length } \sim \text { curvature }+ \text { slope }+\mathbf{s}(\text { (rng25) }+\mathrm{s}(\text { reef }) \\
+\mathrm{s}(\text { vegetation })\end{array}$ & 54.6 & 19.3 \\
\hline Coris auricularis & $\begin{array}{l}\text { Length } \sim \mathrm{s}(\text { eastness })+\mathrm{s}(\text { northness })+\mathrm{s}(\text { profile }) \\
+\mathrm{s}(\text { slope })+\mathrm{s}(\text { reef })+\mathrm{s}(\text { (rng } 25)+\mathrm{s}(\text { sessinvert }) \\
+\mathrm{s}(\text { vegetation })+\mathrm{s}(\text { seagrass }) \\
\text { Length } \sim \text { vegetation }+ \text { profile }+\mathrm{s}(\text { reef })+\mathrm{s}(\text { sessinvert }) \\
+\mathbf{s}(\text { slope })\end{array}$ & 15.8 & 20.4 \\
\hline Parupeneus chrysopleuron & $\begin{array}{l}\text { Length } \sim \mathrm{s}(\text { eastness })+\mathrm{s}(\text { northness })+\mathrm{s}(\text { curvature }) \\
+\mathrm{s}(\text { reef })+\mathrm{s}(\text { rng } 25)+\mathrm{s}(\text { slope })+\mathrm{s}(\text { bathymetry }) \\
+\mathrm{s}(\text { vegetation })+\mathrm{s}(\text { sessinvert })+\mathrm{s}(\text { seagrass }) \\
\text { Length } \sim \mathbf{s}(\text { bathymetry })+\mathbf{s}(\text { rng } 25)\end{array}$ & 21.1 & 18.2 \\
\hline Torquigener vicinus & $\begin{array}{l}\text { Length } \sim \mathrm{s}(\text { eastness })+\mathrm{s}(\text { northness })+\mathrm{s}(\text { curvature }) \\
+\mathrm{s}(\text { reef })+\mathrm{s}(\text { slope })+\mathrm{s}(\text { bathymetry })+\mathrm{s}(\text { vegetation }) \\
+\mathrm{s}(\text { sessinvert }) \\
\text { Length } \sim \text { reef }+\mathrm{s} \text { (eastness })\end{array}$ & 13.6 & 23.1 \\
\hline Chrysophrys auratus & $\begin{array}{l}\text { Length } \sim \mathrm{s}(\text { eastness })+\mathrm{s}(\text { northness })+\mathrm{s}(\text { profile }) \\
+\mathrm{s}(\text { bathymetry })+\mathrm{s}(\text { reef })+\mathrm{s}(\mathrm{rng} 25)+\mathrm{s}(\text { kelp }) \\
+\mathrm{s}(\text { vegetation })+\mathrm{s}(\text { sand })+\mathrm{s}(\text { seagrass }) \\
\text { Length } \sim \mathbf{s}(\text { eastness })+\mathbf{s}(\text { rng } 25)+\mathbf{s}(\text { bathymetry }) \\
+\mathbf{s}(\text { reef })+\mathbf{s}(\text { vegetation })\end{array}$ & 53.2 & 18.9 \\
\hline Pentapodus vitta & $\begin{array}{l}\text { Length } \sim \mathrm{s}(\text { eastness })+\mathrm{s}(\text { northness })+\mathrm{s} \text { (profile) } \\
+\mathrm{s}(\text { bathymetry })+\mathrm{s}(\text { reef })+\mathrm{s}(\text { rng } 25)+\mathrm{s}(\text { slope }) \\
+\mathrm{s}(\text { vegetation })+\mathrm{s}(\text { sessinvert }) \\
\text { Length } \sim \mathbf{s}(\text { eastness })+\mathbf{s} \text { (northness) + s(rng25) } \\
+\mathbf{s}(\text { bathymetry) + s(vegetation) }\end{array}$ & 20.8 & 13.5 \\
\hline
\end{tabular}

Notes: Initial models are in lightface type. Final models are in boldface type. All explanatory variables were fitted with smooths (knots) $k=3$. When the smoothing symbol ("s") does not appear in the final model, that term was fit as parametric function. Summary of the environmental predictors is provided in the Table 2.

species. The normalized difference between the predicted and observed size values (normalized RMSE) for all models varied between $13.5 \%$ and $23.1 \%$ (Table 3 ). Higher error values were associated with lower explained deviance, suggesting poor model fits for Torquigener vicinus and Coris auricularis.

The presence of reef and vegetation and the habitat structural complexity (reef, veget, and rng25, respectively) were the most common variables chosen by the fitted models across all modelled species (Table 3). The large individuals of Lethrinus genivittatus and Chrysophrys auratus were predicted to be positively associated with the presence of reef and vegetation and high structural complexity (Fig. 2). In addition, high structural complexity and presence of vegetation were positively associated with large individuals of Pentapodus vitta and presence of reef was positively associated with large individuals of Torquigener vicinus (Fig. 2). In contrast, small individuals of Coris auricularis were predicted to be associated with presence of reef and vegetation and small individuals of Parupeneus chrysopleuron were predicted to be associated with high structural complexity of habitat. Large individuals of both species were associated with open areas of low structural complexity (Fig. 2). Bathymetry was an additional environmental variable that appeared in models for three species. The smaller individuals of Pentapodus vitta, Chrysophrys auratus, and Parupeneus chrysopleuron were predicted to be associated primarily with shallow water (Table 3 and Fig. 2).

\section{Spatial predictions}

While a degree of mixing between large and small size individuals was apparent for all six species, the spatial predictions of the habitat associations from the GAM models consistently showed spatial separation between large and small size individuals (Fig. 3). The small size individuals of Lethrinus genivittatus were predicted to be found in the structurally complex near reef areas throughout most of study Area 1 and were particularly concentrated in the northeast and southeast corners of Area 1 and in the western part of study Area 2 (Fig. 3a, b). Large individuals of this species were mostly predicted to be associated with exposed near reef areas covered with vegetation in the central and southwest parts of Area 1 and throughout most of Area 2 (Fig. 3a, b).

Small size Coris auricularis were predicted at near reef areas with a low cover of sessile invertebrates and a high probability of vegetative cover in the northwestern, southern, and central part of Area 1 and also in the central part of Area 2. In contrast, the larger individuals of this species were predicted to be associated with areas of low vegetative cover and medium reef complexity 

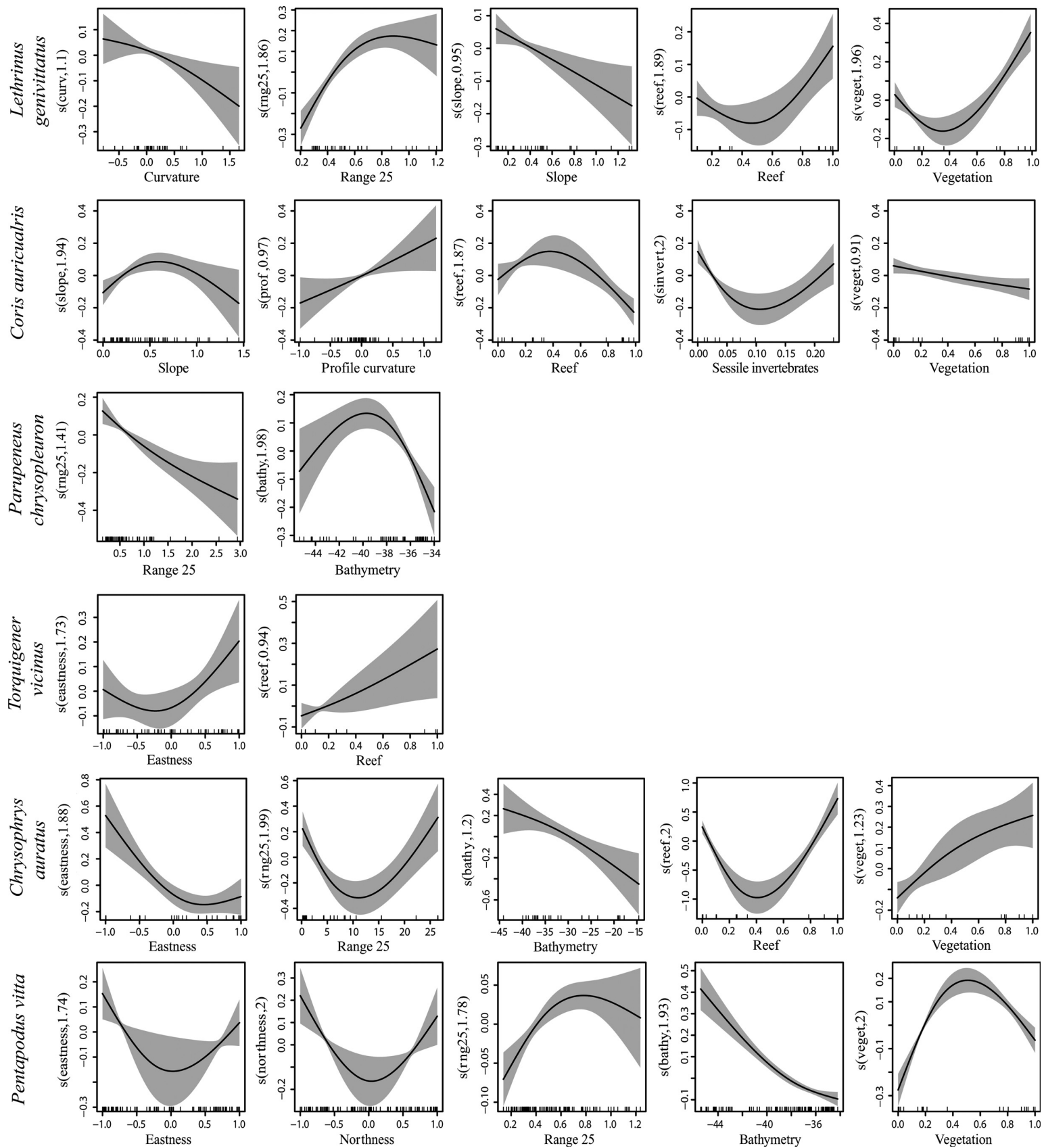

FIG. 2. Smoother estimates (s, solid line) for the environmental predictors as obtained by generalized additive models for individuals of various body lengths of the six study fish species. The approximate $95 \%$ confidence envelopes are indicated (gray shading), marks along the $x$-axis are sampled data points. All explanatory variables were fitted with model smooths (knots) $k=3$. Summary of the environmental predictors is provided in Table 2.

throughout Area 2 and the northeast and southeast parts of Area 1 (Fig. 3c, d).

Water depth was important for Parupeneus chrysopleuron with medium to small size individuals of this species predicted to be scattered over reef slopes at intermediate water depths in the northwest, southeast, and central parts of Area 1 and in the western part of Area
2. The larger size individuals of this species were predicted to be found throughout both study areas in deep water habitats characterized by low structural complexity (Fig. 3e, f).

The exposed east facing reef areas throughout the central part of Area 2 and in a few distinctive patches in the central and north-western parts of Area 1 were 

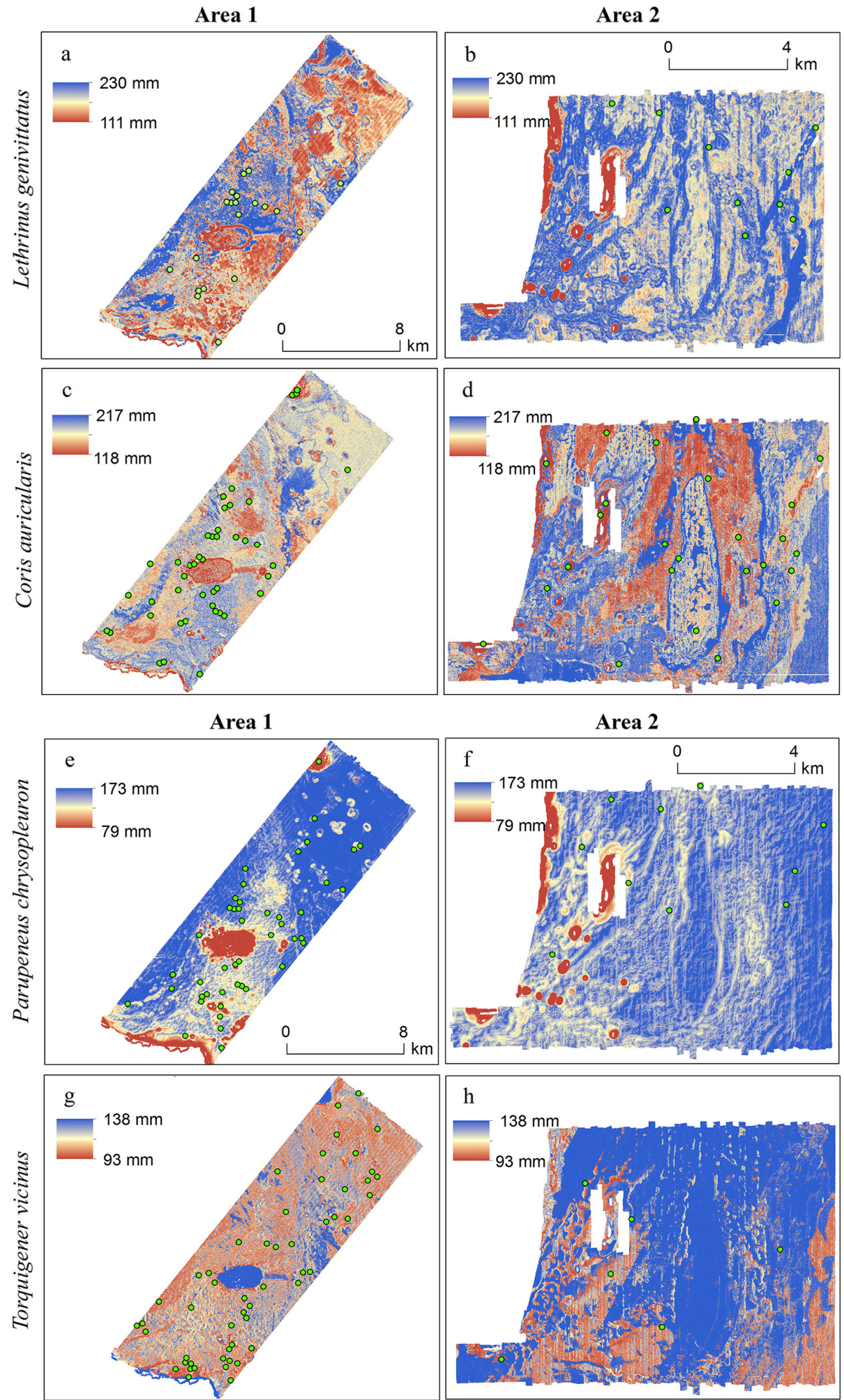

FIG. 3. Predictive maps of habitat associations on a continuous size scale of individuals of the six study species as obtained by generalized additive models predicted on a $2.5-\mathrm{m}$ grid. Positions of species-specific observations from the individual baited remote underwater stereo-video systems (stereo-BRUVs) surveys are marked by green circles. 
Area 1
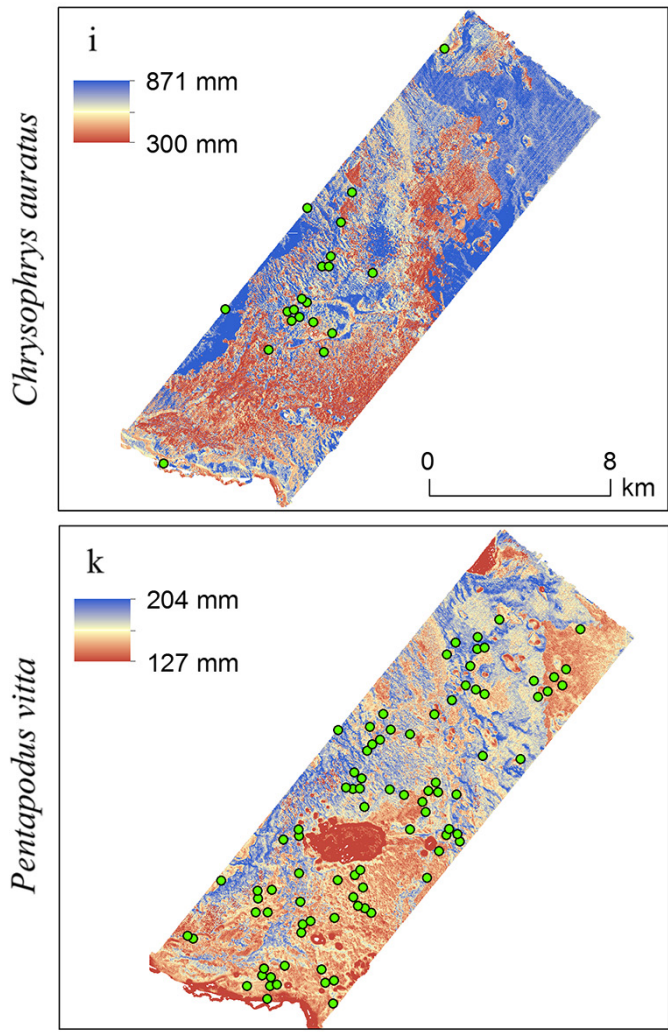

Area 2

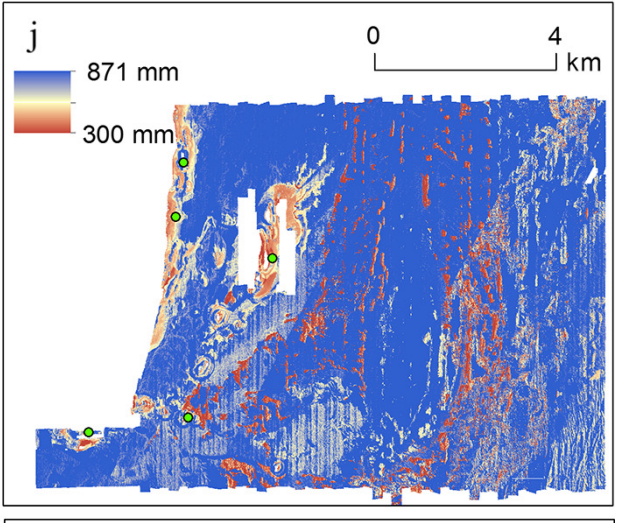

1

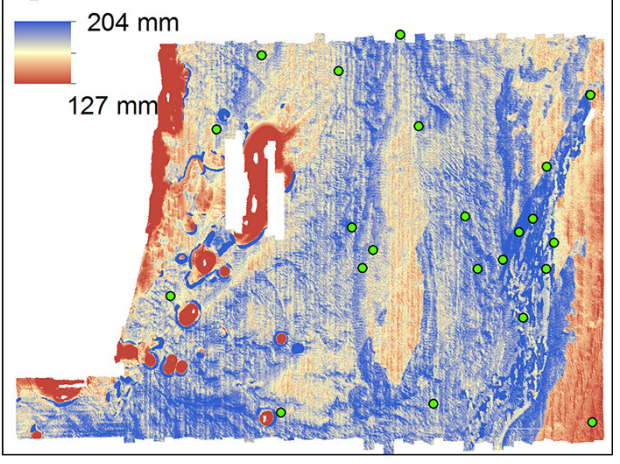

FIG. 3. Continued.

predicted to be suitable for large sized individuals of Torquigener vicinus. In contrast, the small sized individuals of this species were predicted to be found throughout most of Area 1 and on protected flat patches in the west and east parts of Area 2 (Fig. 3g, h).

The larger sized individuals of Chrysophrys auratus were predicted to be associated with west-facing deep reef slopes covered by dense vegetation throughout most of Area 2 and the northern and western parts of Area 1. In contrast, smaller sized individuals of this species were predicted to be scattered throughout shallow, bare, east facing reef flats in the central part of Area 2 and in the central-south part of Area 1 (Fig. 3i,j).

Both study areas were predicted to be highly suitable for small to medium size individuals of Pentapodus vitta. Protected reef flats at intermediate depths in the northwest, central and south of Area 1 and the western and eastern sides of Area 2 were predicted to be particularly suitable for small size individuals of this species. The large size individuals of this species were mostly predicted to be associated with deep high complexity reef slopes covered by vegetation throughout the central and eastern parts of Area 2 (Fig. 3k, 1).

Cumulative predicted fish distribution maps of the six study species combined identified hotspots of environmental niche conditions suitable for species aggregations of juvenile fish and adult fish in the study region. The spatial distribution of hotspots for adults and juveniles showed opposing patterns (Fig 4). Environmental niche conditions suitable for juvenile fish were predicted in the south-eastern part of Area 1 and in the many shallow pockets scattered throughout the area. In Area 2 conditions suitable for juveniles were predicted around the shallow reef edges in the western part of the study area (Fig. 4a, b). In contrast, hotspots for species aggregations of adult fish were predicted in deeper, less structurally complex regions around the center and north of study Area 1. In Area 2 environmental niche conditions suitable for adult fish were predicted in the eastern and the western regions of the area (Fig. 4c, d).

\section{DiscusSION}

\section{Methodological approach}

This case study successfully combined highly precise continuous fish length data obtained using stereoBRUVs with modelled habitat maps derived from ground-truthed data to produce predictive maps of ontogenetic environmental niche associations of six abundant fish species with varying degrees of ecological and commercial importance. When examined next to each other, 
Juvenile Fish
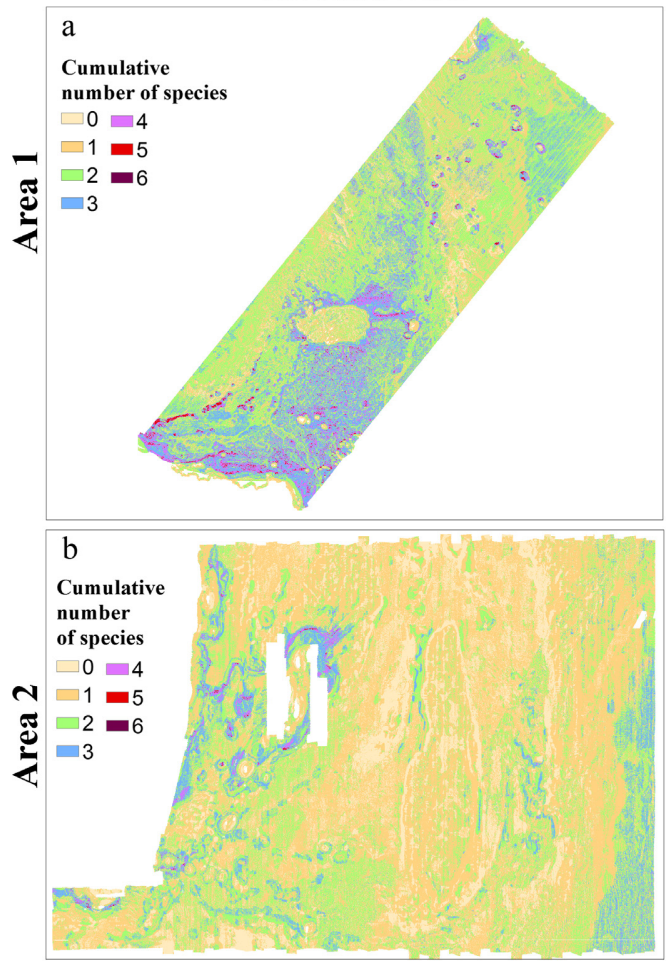

Adult Fish
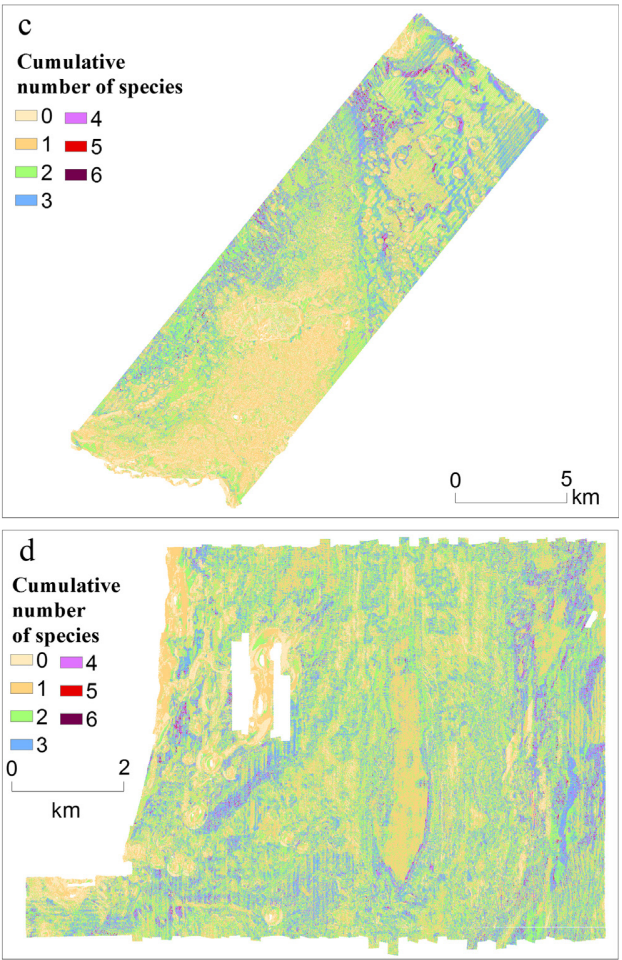

FIG. 4. Hotspots map for cumulative environmental niche suitability for ( $a, b)$ juvenile/small and (c, d) adult/large individuals of the six study species. Fish size classes for the rasters were assigned based on known ontogeny of the study species. There is apparent habitat partitioning between fishes of different life history stages/body lengths, suggesting ontogenetic shifts in habitat use for all six species.

these maps highlight habitat partitioning with body length for all study species. These maps graphically represent ontogenetic shifts in habitat use.

We acknowledge that it is desirable to connect between patterns of fish abundance and the modelled environmental niche associations with size. However, currently two stage analysis using GAMs with gamma error distribution is not possible. We aware of only one statistical package that is currently under development that will potentially be able to incorporate two stage hurdle GAMs for modelling species abundance and continuous body length (see Yee [2015] for details about the package). Such an analysis would be a useful and logical extension of our work.

\section{Habitat distribution of studied species}

Fitting GAMs is a flexible modelling approach suitable for demersal fishes (Valavanis et al. 2008). The individual models fitted varied in their explanatory and predictive performance. The lowest deviance explained and the highest predictive errors were observed for models of size distributions fitted to Coris auricularis and Torquigener vicinus. The most plausible explanation for this poor model performance is related to the biological characteristics of these species, where mixed schools contain both juveniles and adults. This has been documented for Coris auricularis, where various size females of this species come together under male-dominated harems or set up cleaning stations to remove skin parasites from other fish (Lek et al. 2012, Saunders et al. 2013).

High structural complexity provided by the reefs and canopy forming seaweeds were found to be among the most common environmental variables that drove the patterns in size distributions of the modelled species. These habitats are known to drive the distribution of fish species due to their influence on many demographic and community processes, for example, by providing different sized shelters (Wilson et al. 2007, Nash et al. 2013), food sources (Lim et al. 2016), and nesting spaces (Azevedo et al. 1999) to individuals with varying degrees of habitat specialization (Munday 2004). These processes could explain the close associations of large individuals of four of the modelled species with deep reef habitats. Juvenile survivorship on deep reefs is typically lower than in shallow near shore areas (Kimirei et al. 2013), a situation that is likely to favor higher abundance of larger individuals. In contrast, small individuals of Coris auricularis and Parupeneus chrysopleuron were predicted to be associated with reefs and macroalgal 
habitats. Reef and macroalgal habitats support high density and diversity of fish assemblages (Bellwood et al. 2003, Mellin et al. 2007), are important recruitment areas (Jones 1984b) or juvenile habitats (Evans et al. 2014, Grol et al. 2014) and contribute to adult population patterns (Huijbers et al. 2013).

\section{Applicability of findings to spatial management}

Understanding spatial population dynamics of marine animals is a vital step for successful spatial management. Collection of field data is often limited due to restricted resources for monitoring, and fish populations are often patchily distributed in space and time (e.g., Newman and Williams 2001, Travers et al. 2012). Therefore, predictive spatial modelling is a powerful tool because it allows data extrapolation into unsampled areas.

Mapping key areas such as fish nurseries or hotspots for multiple species aggregations can identify environmental niche requirements and resource partitioning between fish at different life stages. The geographic distribution and productivity of nursery areas are important drivers for the spatial distribution patterns of adult populations, where areas close to nurseries replenish more isolated areas (Huijbers et al. 2013). In addition, well-established global biodiversity patterns are changing rapidly in response to human activities such as ocean warming (Sala and Knowlton 2006). To effectively address such issues, managers require advanced tools to identify geographic areas that have a high intrinsic management value. Our method for identifying hotspot areas demonstrates a useful decision support tool for spatially identifying benthic areas that are important for numerous species and/or for different life stages of multiple species (e.g., fish nurseries). Following in situ evaluation of the predicted hotspots, the hotspot maps can identify entire areas that may not require future in-depth surveys, thus optimizing limited management resources. Hotspot areas could be considered in zoning schemes and become priority areas for marine spatial monitoring and management (Schmiing et al. 2013). In addition, future re-zoning efforts should consider including hotspot areas. In conclusion, robust size-based predictive ecological modelling can further improve our knowledge of the spatial habitat use of demersal fishes at various life history stages. In turn this knowledge will contribute to marine spatial management efforts for rapid assessment and development of mitigation strategies for declining ecosystem condition.

\section{ACKNOWLEDGMENTS}

The data used in this manuscript was collected through funding provided by an Australian and Western Australian Government Natural Heritage Trust Strategic Project, "Securing Western Australia's Marine Futures." We thank South Coast Natural Resource Management for access to the data and the staff of the Marine Futures team who collected the data, in particular, Simon Grove, Paul Kennedy, Tim Langlois, Ben Piek, Heather Taylor, and Kimberly Van Niel. Vessel support was provided by the Department of Fisheries WA (Geraldton,
Mathew Robinson and Greg Finlay) and Latitude Fisheries (Pia Boschetti). We also acknowledge two anonymous reviewers from the WA Department of Fisheries.

\section{Literature Cited}

Austin, M. 2007. Species distribution models and ecological theory: a critical assessment and some possible new approaches. Ecological Modelling 200:1-19.

Azevedo, J. M. N., H. I. R. Cepeda, and J. B. Rodrigues. 1999. Notes on the biology of Centrolabrus caeruleus Azevedo, 1999 (Teleostei: Labridae). Arquipelago Life Marine Science 17A:27-36.

Bellwood, D. R., A. S. Hoey, and J. H. Choat. 2003. Limited functional redundancy in high diversity systems: resilience and ecosystem function on coral reefs. Ecology Letters 6:281-285.

Bornt, K. R., D. L. McLean, T. J. Langlois, E. S. Harvey, L. M. Bellchampbers, S. N. Evans, and S. J. Newman. 2015. Targeted demersal fish species exhibit variable responses to long-term protection from fishing at the Houtman Abrolhos Islands. Coral Reefs 34:1297-1312.

Boström, C., S. J. Pittman, C. Simenstad, and R. T. Kneib. 2011. Seascape ecology of coastal biogenic habitats: advances, gaps, and challenges. Marine Ecology Progress Series 427: 191-217.

Compton, T. J., M. A. Morrison, J. R. Leathwick, and G. D. Carbines. 2012. Ontogenetic habitat associations of a demersal fish species, Pagrus auratus, identified using boosted regression trees. Marine Ecology Progress Series 462:219-230.

Costa, B., J. C. Taylor, L. Kracker, T. Battista, and S. Pittman. 2014. Mapping reef fish and the seascape: using acoustics and spatial modeling to guide coastal management. PLoS ONE 9: e85555.

Drexler, M., and C. H. Ainsworth. 2013. Generalized additive models used to predict species abundance in the Gulf of Mexico: an ecosystem modeling tool. PLoS ONE 8:e64458.

Dugan, J. E., and G. E. Davis. 1993. Applications of marine refugia to coastal fisheries management. Canadian Journal of Fisheries and Aquatic Sciences 50:2029-2042.

Elith, J., and J. R. Leathwick. 2009. Species distribution models: ecological explanation and prediction across space and time. Annual Review of Ecology, Evolution, and Systematics 40:677-697.

Evans, R. D., S. K. Wilson, and S. N. Field. 2014. Importance of macroalgal fields as coral reef fish nursery habitat in north-west Australia. Marine Biology 161:599-607.

Grol, M. G. G., A. L. Rypel, and I. Nagelkerken. 2014. Growth potential and predation risk drive ontogenetic shifts among nursery habitats in a coral reef fish. Marine Ecology Progress Series 502:229-244.

Halpern, B. S., S. D. Gaines, and R. R. Warner. 2005. Habitat size, recruitment, and longevity as factors limiting population size in stage-structured species. American Naturalist 165:82-94.

Harvey, E. S., M. Cappo, and G. A. Kendrick. 2013. Coastal fish assemblages reflect geological and oceanographic gradients within an Australian zootone. PLoS ONE 8:e80955.

Harvey, E., D. Fletcher, and M. Shortis. 2002. Estimation of reef fish length by divers and by stereo-video: a first comparison of the accuracy and precision in the field on living fish under operational conditions. Fisheries Research 57:255-265.

Harvey, E., and M. Shortis. 1995. A system for stereo-video measurement of sub-tidal organisms. Marine Technology Society Journal 29:10-22.

Harvey, E., and M. Shortis. 1998. Calibration stability of an underwater stereo-video system: implications for measurement accuracy and precision. Marine Technology Society Journal 32:3-17. 
Hastie, T. J., and R. J. Tibshirani. 1990. Generalized additive models. Volume 43. CRC Press, London.

Hesterberg, T., N. H. Choi, L. Meier, and C. Fraley. 2008. Least angle and 11 penalized regression: a review. Statistics Surveys 2:61-93.

Huijbers, C. M., I. Nagelkerken, A. O. Debrot, and E. Jongejans. 2013. Geographic coupling of juvenile and adult habitat shapes spatial population dynamics of a coral reef fish. Ecology 94:1859-1870.

Huijbers, C. M., I. Nagelkerken, and C. A. Layman. 2015. Fish movement from nursery bays to coral reefs: A matter of size? Hydrobiologia 750:89-101.

Hutchins, B. J. 2001. Biodiversity of shallow reef fish assemblages in Western Australia using a rapid censusing technique. Records of the Western Australian Museum 20:247-270.

Hutchinson, G. E. 1957. Concluding remarks: Cold Spring Harbor symposia on quantitative biology. Pages 415-427. Cold Spring Harbor Lab Press, NY, USA.

IMCRA. 1998. Interim Marine and Coastal Regionalisation for Australia: an ecosystem-based classification for marine and coastal environments. Version 3.3. Commonwealth Department of the Environment, Canberra, Australian Capital Territory, Australia.

Jones, G. P. 1984a. Population ecology of the temperate reef fish Pseudolabrus celidotus Bloch \& Schneider (Pisces: Labridae). I. Factors influencing recruitment. Journal of Experimental Marine Biology and Ecology 75:257-276.

Jones, G. P. 1984b. The influence of habitat and behavioral interactions on the local distribution of the wrasse Pseudolabrus celidotus. Environmental Biology of Fishes 10:43-58.

Jones, G. P., M. I. McCormick, M. Srinivasan, and J. V. Eagle. 2004. Coral decline threatens fish biodiversity in marine reserves. Proceedings of the National Academy of Sciences USA 101:8251-8253.

Kangas, M. I., S. Morrison, P. Unsworth, E. Lai, I. Wright, and A. Thomson. 2007. Development of biodiversity and habitat monitoring systems for key trawl fisheries in Western Australia. Final Report to Fisheries Research and Development Corporation on Project No. 2002/038. Fisheries Research Report No. 160, Department of Fisheries, North Beach, Western Australia, Australia.

Kimirei, I. A., I. Nagelkerken, M. Trommelen, P. Blankers, N. van Hoytema, D. Hoeijmakers, C. M. Huijbers, Y. D. Mgaya, and A. L. Rypel. 2013. What drives ontogenetic niche shifts of fishes in coral reef ecosystems? Ecosystems 16:783-796.

Kingsford, M. J., and I. J. Carlson. 2010. Patterns of distribution and movement of fishes, Ophthalmolepis lineolatus and Hypoplectrodes maccullochi, on temperate rocky reefs of south eastern Australia. Environmental Biology of Fishes 88:105-118.

Lauria, V., S. Vaz, C. S. Martin, S. Mackinson, and A. Carpentier. 2011. What influences European plaice (Pleuronectes platessa) distribution in the eastern English Channel? Using habitat modelling and GIS to predict habitat utilization. ICES Journal of Marine Science: Journal du Conseil 68:1500-1510.

Leathwick, J. R., J. Elith, and T. Hastie. 2006. Comparative performance of generalized additive models and multivariate adaptive regression splines for statistical modelling of species distributions. Ecological Modelling 199:188-196.

Lek, E., D. V. Fairclough, N. G. Hall, S. A. Hesp, and I. C. Potter. 2012. Do the maximum sizes, ages and patterns of growth of three reef-dwelling labrid species at two latitudes differ in a manner conforming to the metabolic theory of ecology? Journal of Fish Biology 81:1936-1962.

Lim, I. E., S. K. Wilson, T. H. Holmes, M. M. Noble, and C. J. Fulton. 2016. Specialization within a shifting habitat mosaic underpins the seasonal abundance of a tropical fish. Ecosphere 7:e1212.

Lukoschek, V., and M. I. McCormick. 2001. Ontogeny of diet changes in a tropical benthic carnivorous fish, Parupeneus barberinus (Mullidae): relationship between foraging behaviour, habitat use, jaw size, and prey selection. Marine Biology 138:1099-1113.

Mant, J. C., M. J. Moran, S. J. Newman, A. S. Hesp, N. G. Hall, and I. C. Potter. 2006. Biological characteristics and mortality of western butterfish (Pentapodus vitta), an abundant bycatch species of prawn trawling and recreational fishing in a large subtropical embayment. Fishery Bulletin 104: $512-520$.

Marra, G., and S. N. Wood. 2011. Practical variable selection for generalized additive models. Computational Statistics \& Data Analysis 55:2372-2387.

Martin, C. S., S. Vaz, J. R. Ellis, V. Lauria, F. Coppin, and A. Carpentier. 2012. Modelled distributions of ten demersal elasmobranchs of the eastern English Channel in relation to the environment. Journal of Experimental Marine Biology and Ecology 418-419:91-103.

Martinez-Meyer, E., D. Diaz-Porras, A. T. Peterson, and C. Yáñez-Arenas. 2013. Ecological niche structure and rangewide abundance patterns of species. Biology Letters 9: 20120637.

Mellin, C., M. Kulbicki, and D. Ponton. 2007. Seasonal and ontogenetic patterns of habitat use in coral reef fish juveniles. Estuarine, Coastal and Shelf Science 75:481-491.

Moore, C. H., E. S. Harvey, and K. P. Van Niel. 2009. Spatial prediction of demersal fish distributions: enhancing our understanding of species-environment relationships. ICES Journal of Marine Science 66:2068-2075.

Moore, C. H., K. Van Niel, and E. S. Harvey. 2011. The effect of landscape composition and configuration on the spatial distribution of temperate demersal fish. Ecography 34:425435.

Munday, P. L. 2004. Habitat loss, resource specialization, and extinction on coral reefs. Global Change Biology 10: 1642-1647.

Nagelkerken, I. 2007. Are non-estuarine mangroves connected to coral reefs through fish migration? Bulletin of Marine Science 80:595-607.

Nagelkerken, I., M. Sheaves, R. Baker, and R. M. Connolly. 2015. The seascape nursery: a novel spatial approach to identify and manage nurseries for coastal marine fauna. Fish and Fisheries 16:362-371.

Nash, K. L., N. A. J. Graham, S. K. Wilson, and D. R. Bellwood. 2013. Cross-scale habitat structure drives fish body size distributions on coral reefs. Ecosystems 16:478-490.

Newman, S. J., and D. M. Williams. 2001. Spatial and temporal variation in assemblages of Lutjanidae, Lethrinidae and associated fish species among mid-continental shelf reefs in the central Great Barrier Reef. Marine and Freshwater Research 52:843-851.

Olds, A. D., R. M. Connolly, K. A. Pitt, P. S. Maxwell, S. Aswani, and S. Albert. 2014. Incorporating surrogate species and seascape connectivity to improve marine conservation outcomes. Conservation Biology 28:982-991.

Pearce, A., and M. Feng. 2013. The rise and fall of the "marine heat wave" off Western Australia during the summer of 2010/ 2011. Journal of Marine Systems 111:139-156.

Possingham, H., I. Ball, and S. Andelman. 2000. Quantitative methods for conservation biology. Pages 291-306. Springer, New York, New York, USA.

Potts, J. M., and J. Elith. 2006. Comparing species abundance models. Ecological Modelling 199:153-163. 
R Core Team. 2014. R: a language and environment for statistical computing. R Foundation for Statistical Computing, Vienna, Austria.

Radford, B. T., K. P. Van Niel, and K. W. Holmes. 2008. WA Marine Futures: Benthic Modelling and Mapping Final Report. The University of Western Australia, Perth, Western Australia, Australia.

Sagarese, S. R., M. G. Frisk, R. M. Cerrato, K. A. Sosebee, J. A. Musick, and P. J. Rago. 2014. Application of generalized additive models to examine ontogenetic and seasonal distributions of spiny dogfish (Squalus acanthias) in the Northeast (US) shelf large marine ecosystem. Canadian Journal of Fisheries and Aquatic Sciences 877:847-877.

Sala, E., and N. Knowlton. 2006. Global marine biodiversity trends. Annual Review of Environment and Resources 31: 93-122.

Saunders, B. J., E. S. Harvey, and G. A. Kendrick. 2013. Nesting behaviour of a temperate damselfish (Parma mccullochi) and its influence on algae. Marine and Freshwater Behaviour and Physiology 46:169-182.

Schmiing, M., P. Afonso, F. Tempera, and R. S. Santos. 2013. Predictive habitat modelling of reef fishes with contrasting trophic ecologies. Marine Ecology Progress Series 474:201-216.

Smallwood, C. B., A. Hesp, and L. E. Beckley. 2013. Biology, stock status and management summaries for selected fish species in south-western Australia. Fisheries Research Division, Western Australian Fisheries and Marine Research Laboratories, Perth, Australia.

Travers, M. J., I. C. Potter, K. R. Clarke, and S. J. Newman. 2012. Relationships between latitude and environmental conditions and the species richness, abundance and composition of tropical fish assemblages over soft substrata. Marine Ecology Progress Series 446:221-241.

Valavanis, V. D., G. J. Pierce, A. F. Zuur, A. Palialexis, A. Saveliev, I. Katara, and J. Wang. 2008. Modelling of essential fish habitat based on remote sensing, spatial analysis and GIS. Hydrobiologia 612:5-20.

Watson, D. L., M. J. Anderson, G. A. Kendrick, K. Nardi, and E. S. Harvey. 2009. Effects of protection from fishing on the lengths of targeted and non-targeted fish species at the Houtman Abrolhos Islands, Western Australia. Marine Ecology Progress Series 384:241-249.

Wilson, S. K., N. A. J. Graham, and N. V. C. Polunin. 2007. Appraisal of visual assessments of habitat complexity and benthic composition on coral reefs. Marine Biology 151:1069-1076.

Wood, S. N. 2006. Generalized additive models: an introduction with R. Chapman\& Hall/CRC, Boca Raton, Florida, USA.

Yee, T. W. 2015. VGAM: vector generalized linear and additive models. R package version 1.0-0. http//www.stat.auckland.ac. nz/yee/VGAM

Zuur, A. F., E. N. Ieno, and C. S. Elphick. 2010. A protocol for data exploration to avoid common statistical problems. Methods in Ecology and Evolution 1:3-14.

Zuur, A. F., E. N. Ieno, and G. M. Smith. 2007. Analysing ecological data. Series: Statistics for biology and health. Springer, New York, New York, USA.

Zuur, A., E. N. Ieno, N. Walker, A. A. Saveliev, and G. M. Smith. 2009. Mixed effects models and extensions in ecology with R. Springer Science \& Business Media, NY, USA.

\section{Data Availability}

Data associated with this paper are available from the University of Western Australia Marine Futures repository http://matrixprod.its.uwa.edu.au/marinefutures/research/project/abrolhos 